Supporting Information

\title{
Microwave hydrophobized lignin with antioxidant activity for fused filament fabrication
}

Jenevieve Yao, Karin Odelius and Minna Hakkarainen*

Department of Fibre and Polymer Technology, KTH Royal Institute of Technology, Teknikringen 56, 10044 Stockholm, Sweden.

Corresponding author: minna@kth.se

This supporting information contains 5 figures and 2 tables on 6 pages. 
Table S1. OH group content in unmodified alkali lignin (AL), acetylated (A) and hexanoated (H) lignin samples, as determined by ${ }^{31} \mathrm{P}$ NMR.

\begin{tabular}{cccccc}
\multirow{2}{*}{$\begin{array}{c}\text { Lignin } \\
\text { sample }\end{array}$} & Aliphatic & Phenolic & $\begin{array}{c}\text { Phenolic }+ \\
\text { Aliphatic }\end{array}$ & COOH & DS (\%) \\
\cline { 2 - 5 } & 2.00 & 2.31 & 4.32 & 0.73 & N/A \\
AL & 0.11 & 0.25 & 0.35 & 1.37 & 90.4 \\
A1 & 0.04 & 0.07 & 0.11 & 0.42 & 97.0 \\
A2 & 0.12 & 0.21 & 0.34 & 0.54 & 90.9 \\
A3 & 0.13 & 0.09 & 0.22 & 0.23 & 93.0 \\
H1 & 0.04 & 0.02 & 0.06 & 0.16 & 98.1 \\
H2 & 0.13 & 0.04 & 0.17 & 0.12 & 94.6 \\
H3 & & & & &
\end{tabular}

Table S2. Molecular weight data of neat PLA filaments extruded at processing conditions corresponding to those used in the extrusion of varying compositions of PLA/lignin blend filaments. PC 1 indicates the processing condition used for 90:10 wt/wt\% PLA/lignin (extrusion temperature from zones 1 to 4, chronologically, of 180-190-200-200 ${ }^{\circ} \mathrm{C}$ and $3 \mathrm{rpm}$ screw speed), PC 2 for 70:30 wt/wt\% PLA/lignin (185-200-205-200 ${ }^{\circ} \mathrm{C}$ and $5 \mathrm{rpm}$ ), and PC 3 for 50:50 wt/wt\% PLA/lignin (185-200-205-200 ${ }^{\circ} \mathrm{C}$ and $\left.10 \mathrm{rpm}\right)$.

$\begin{array}{cccc} & \text { PC 1 } & \text { PC 2 } & \text { PC 3 } \\ \text { Mn (Da) } & 128,000 & 119,000 & 96,600 \\ \mathrm{Mw}(\mathrm{Da}) & 227,000 & 208,000 & 190,000 \\ \mathrm{Mw} / \mathrm{Mn} & 1.8 & 1.7 & 2.0\end{array}$

*Molecular weight data were obtained via chloroform SEC, wherein neat PLA or PLA/lignin blend filaments were dissolved in chloroform for $24 \mathrm{~h}$ and were subsequently filtered through a $0.45 \mu \mathrm{m}$ PTFE filter prior to analysis. 

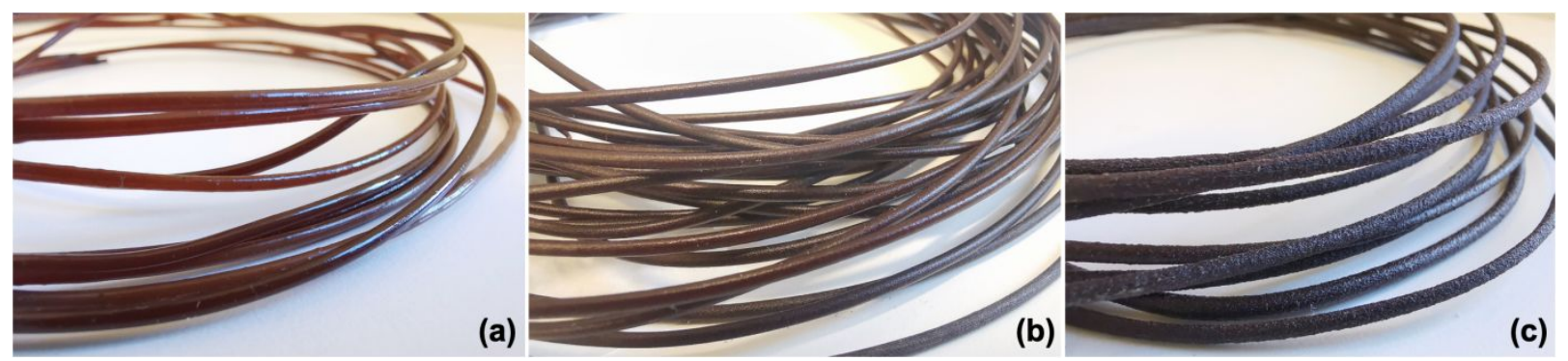

Figure S1. Photos of extruded filaments using acetylated lignin (A2) at blend compositions of:

(a) 90:10, (b) 70:30 and (c) 50:50 (wt/wt\%) PLA/lignin

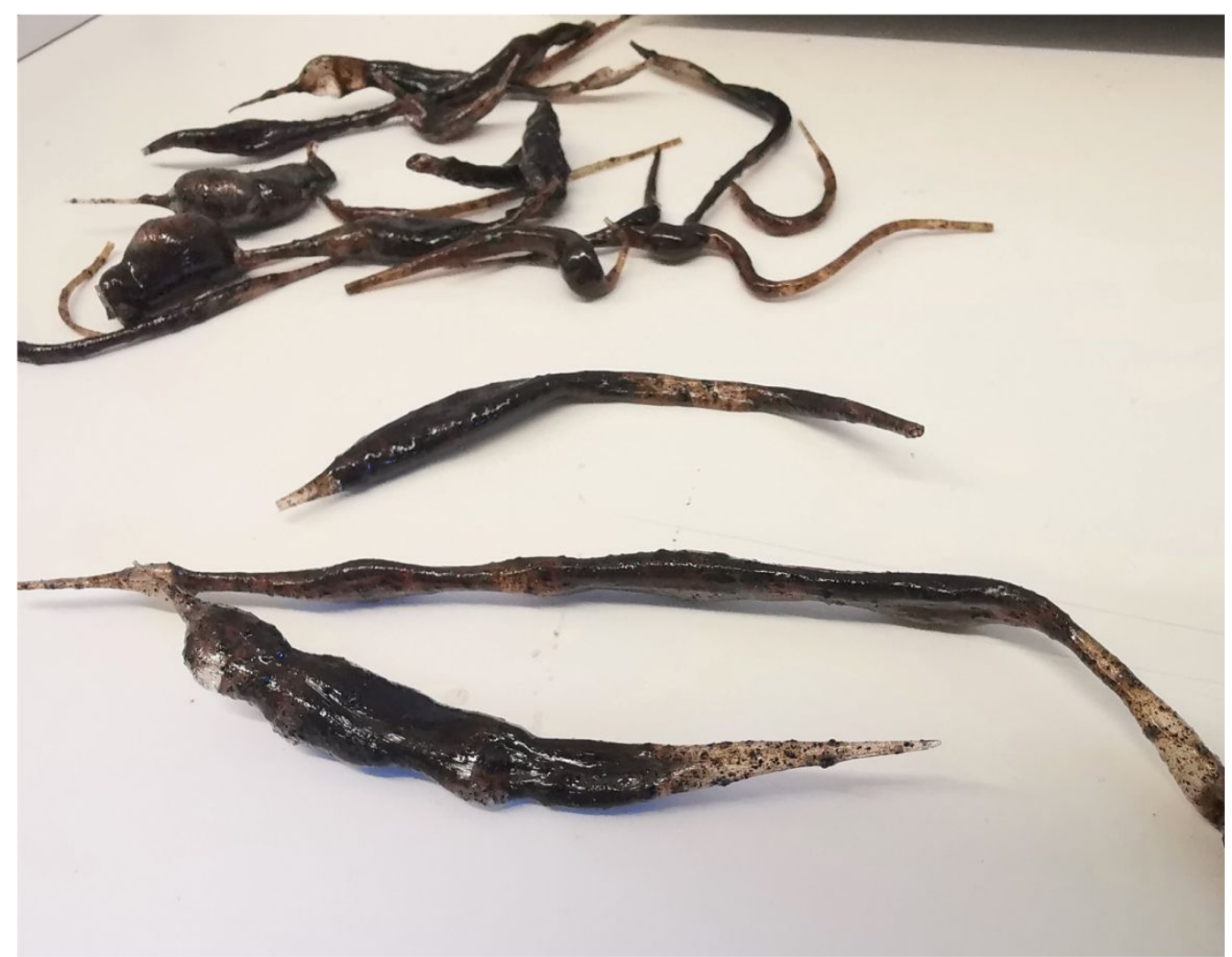

Figure S2. Photo of unsuccessful filaments of PLA/unmodified alkali lignin $(90: 10 \mathrm{wt} / \mathrm{wt} \%)$ blend 


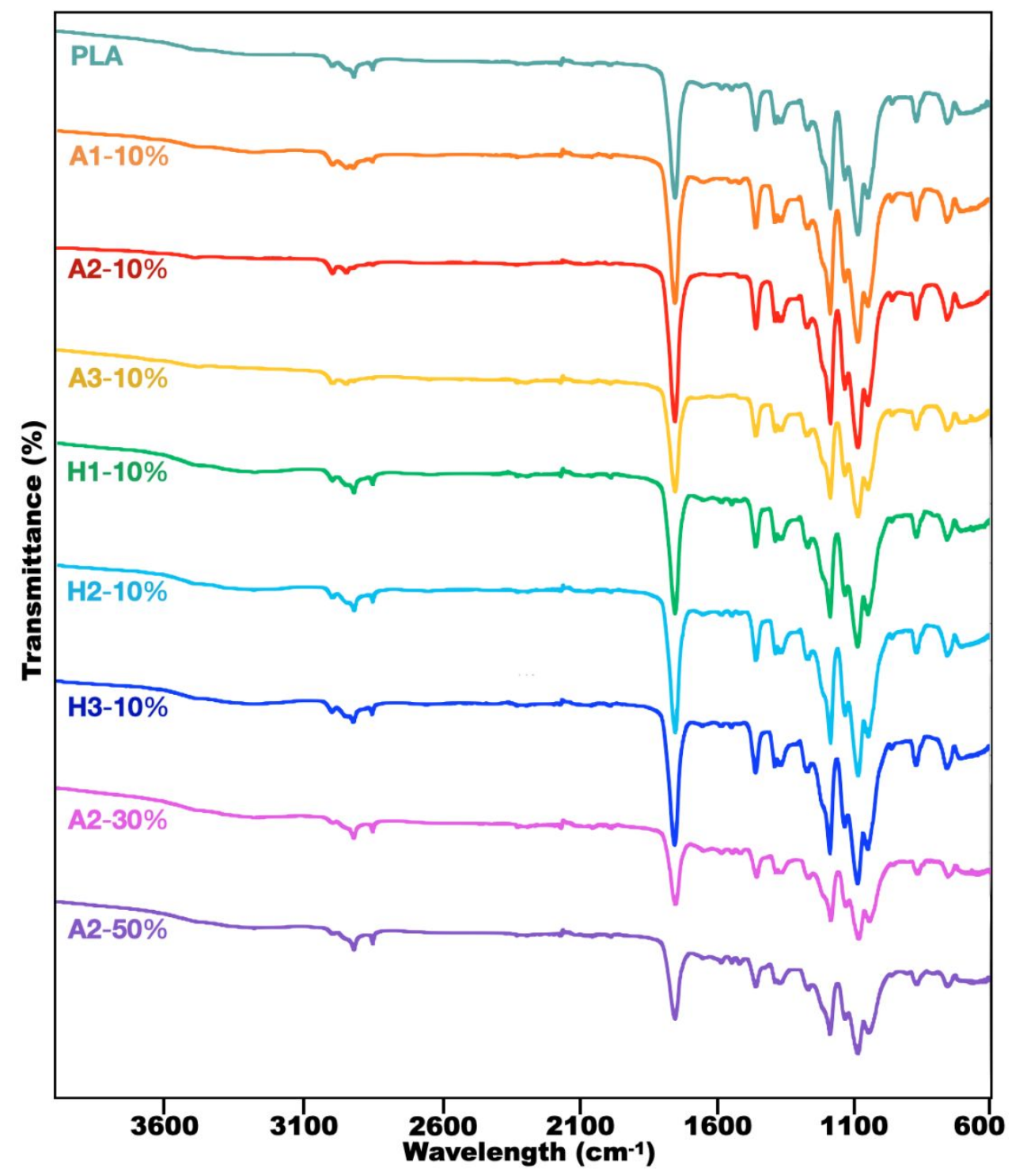

Figure S3. FT-IR spectra of 3D printed PLA/lignin specimens based on blend compositions AX$Y \%$ or $\mathrm{H} X-Y \%$, where $X$ refers to the reaction parameter (1) $110{ }^{\circ} \mathrm{C}$ and $10 \mathrm{~min}$, (2) $130{ }^{\circ} \mathrm{C}$ and $10 \mathrm{~min}$ and (3) $130{ }^{\circ} \mathrm{C}$ and $5 \mathrm{~min}$ and $Y$ stands for the wt\% of acetylated (A) or hexanoated (H) lignin 


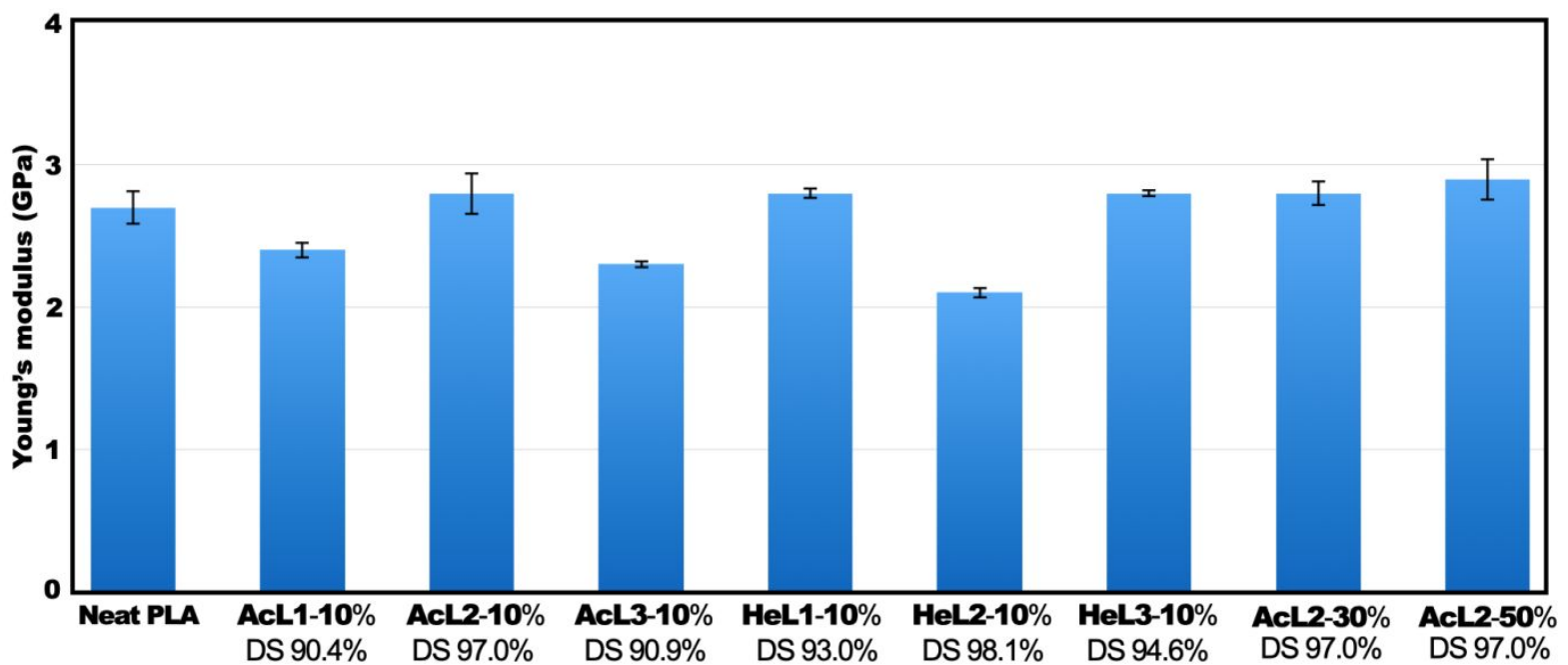

Figure S4. Young's moduli of 3D printed specimens based on PLA/lignin blends containing 10, 30 and $50 \mathrm{wt} \%$ acetylated or hexanoated lignin. 

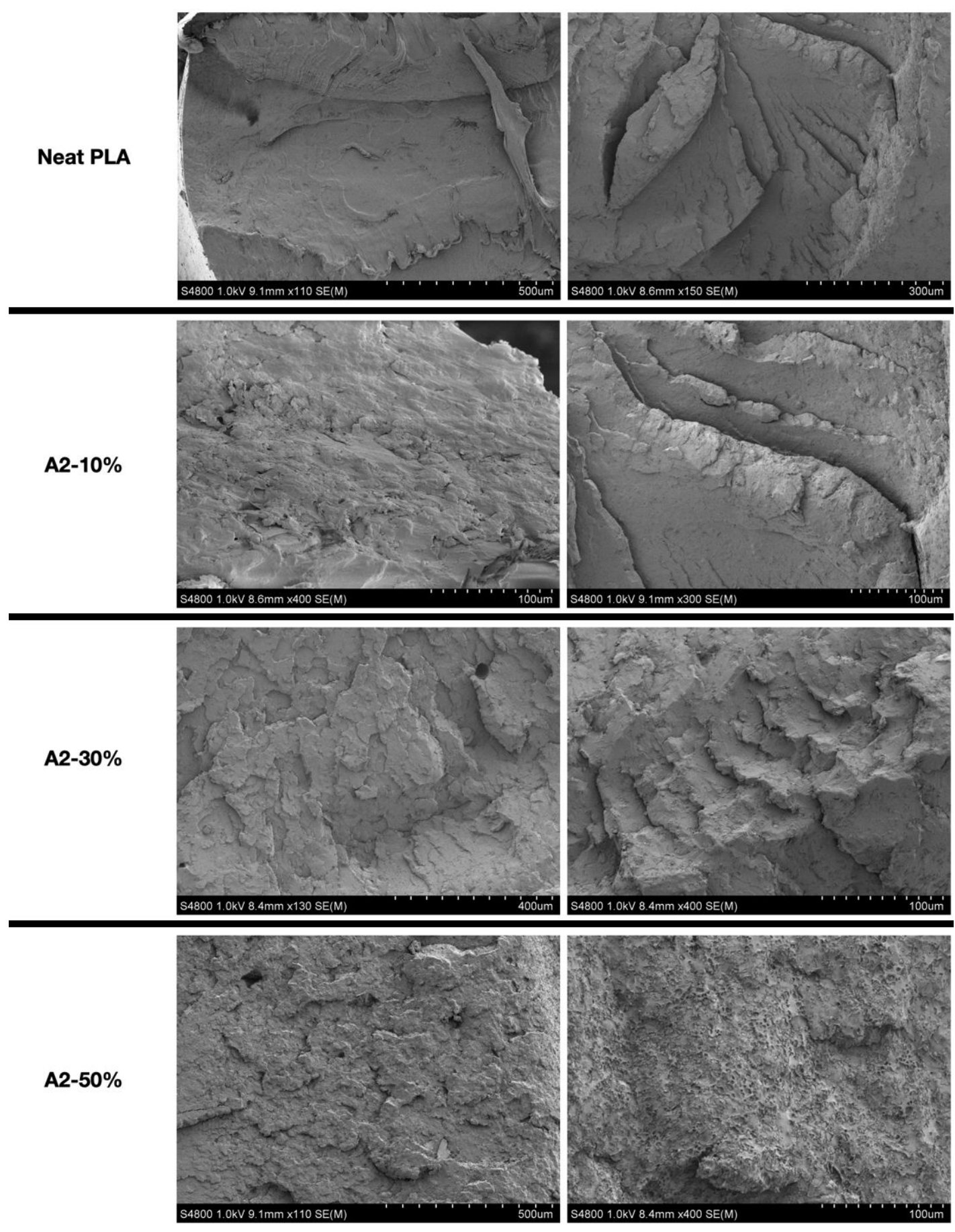

Figure S5. SEM micrographs of filament cross-sections of neat PLA and PLA/acetylated lignin (A2, produced using reaction parameter $130^{\circ} \mathrm{C}$ and $10 \mathrm{~min}$ ) with blend compositions of $10 \mathrm{wt} \%$ (A2-10\%), $30 \mathrm{wt} \%(\mathrm{~A} 2-30 \%)$ and $50 \mathrm{wt} \%(\mathrm{~A} 2-50 \%)$ lignin 